\title{
Endoscopic rendezvous recanalization for complete anastomotic obstruction after retrosternal coloplasty: a novel approach through a cervicotomy
}

A healthy 19 -year-old woman previously underwent a bipolar esophageal exclusion and total gastrectomy following caustic ingestion. After 13 months, she underwent an esophageal replacement by retrosternal left colonic interposition. She subsequently developed complete obstruction of the pharyngocolonic anastomosis. Because blinded antegrade reopening of the mucosa was considered too hazardous, we considered performing a combined antegrade-retrograde endoscopic rendezvous recanalization. Owing to the prior gastrectomy and because of the retrosternal route of the coloplasty, a left cervicotomy was considered to be the best choice for the retrograde access below the anastomosis.

The procedure was performed by two endoscopists and a thoracic surgeon ( $\vee$ Fig. 1 ; $\triangleright$ Video 1$)$. The cervical colon was mobilized through a left cervicotomy, paying particular attention not to compromise its vascular pedicle. A $2-\mathrm{cm}$ colotomy was performed on the tenia coli, allowing antegrade introduction of the endoscope ( $\mathbf{F i g} \mathbf{2} \mathbf{2}$ ). The complete obstruction was identified with the two endoscopes by transillumination. Antegrade puncture using a 19-gauge needle was directed by the retrograde endoscope. After the obstruction had been successfully punctured, a Fil-guide Hydra Jagwire (0.035 inch) was introduced through the obstruction ( $\vee$ Fig. 3 ). Dilation up to $15 \mathrm{~mm}$ was performed using a balloon from the antegrade side, and this was followed by insertion of a nasogastric tube to maintain the patency. The outcome was uneventful. Repeated dilations were required to achieve definitive re-sizing of the anastomosis.

Treatment of cervical anastomotic obstruction after coloplasty for caustic injury is challenging [1-3]. The endoscopic antegrade-retrograde technique appears to be an effective salvage therapy in complete anastomotic obstruction [4]. The most difficult part of the rendez-

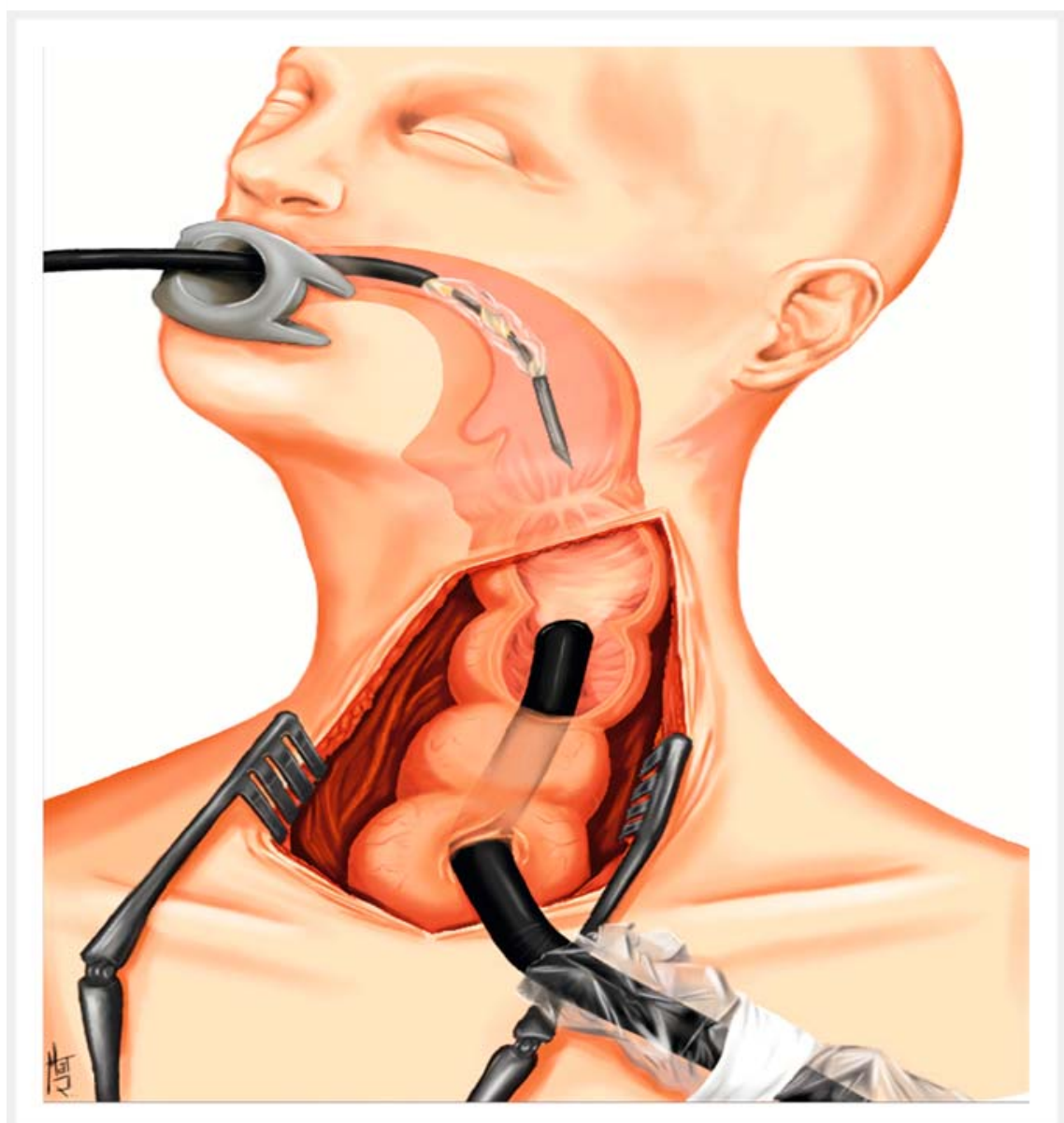

- Fig. 1 Illustration of the antegrade-retrograde rendezvous procedure that was jointly performed by two experienced endoscopists and a thoracic surgeon with the patient under general anesthesia. Two endoscopes with large single channels were introduced through the cervical colon and through the mouth to gain access to the pharyngocolonic anastomosis.

vous procedure is gaining access to the colon below the anastomosis. Normally, a previous percutaneous endoscopic gastrostomy (PEG) is an easy route for the retrograde endoscopy [5]. Our case shows that a cervicotomy could be a simple option to gain access to the retrograde colon below the cervical anastomosis and avoid complex re-intervention in the abdomen.

Endoscopy_UCTN_Code_TTT_1AO_2AN

\section{Competing interests}

The authors declare that they have no conflict of interest. 


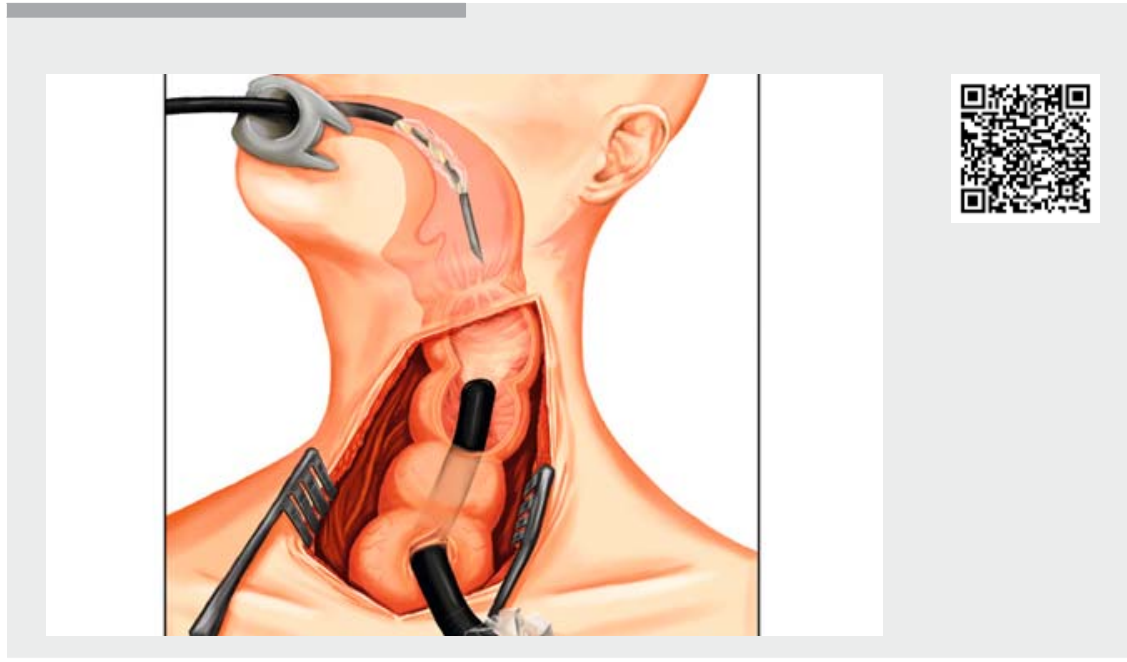

Video 1 Video showing rendezvous recanalization of a completely obstructed pharyngocolonic anastomosis. A cervicotomy was performed to allow access for the retrograde endoscope, which was then used to direct antegrade puncture. After insertion of a guidewire, balloon dilation was performed, with a nasogastric tube inserted once the rendezvous had been achieved.

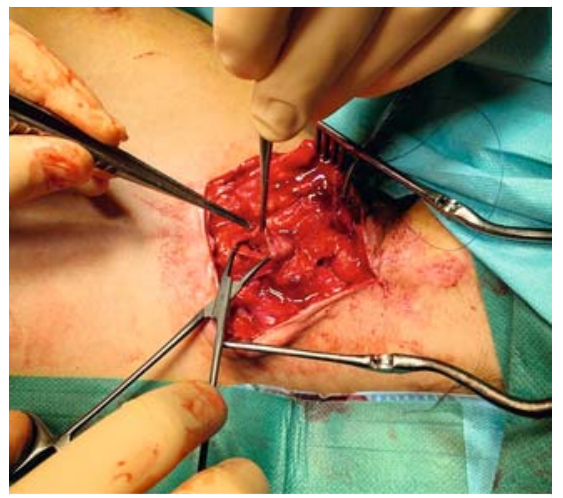

- Fig. 2 Photograph of the left cervicotomy, which allowed access to the $10-\mathrm{cm}$ proximal part of the coloplasty just below the anastomosis. After careful mobilization of the cervical colon, a 2-cm colotomy was performed, so allowing antegrade introduction of a flexible endoscope.

The authors

Michael Baboudjian', Mathieu Rouy', Mohamed Gasmi ${ }^{2}$, Abel Tadrist ${ }^{1}$, Pascal Thomas' ${ }^{1}$, Marc Barthet ${ }^{2}$, Xavier Benoît D'Journo' ${ }^{1}$

1 Department of Thoracic Surgery, North Hospital, Aix-Marseille University, APHM, Marseille, France

2 Department of Hepatogastroenterology, North Hospital, Aix-Marseille University, APHM, Marseille, France
[1] Huang Q, Zhong J, Yang T et al. Impacts of anastomotic complications on the healthrelated quality of life after esophagectomy. J Surg Oncol 2015; 111: 365-370

[2] Pereira-Lima JC, Ramires RP, Zamin I Jr et al. Endoscopic dilation of benign esophageal strictures: report on 1043 procedures. Am J Gastroenterol 1999; 94: 1497-1501

[3] van Boeckel PG, Siersema PD. Refractory esophageal strictures: what to do when dilation fails. Curr Treat Options Gastroenterol 2015; 13: 47-58

[4] Gonzalez JM, Vanbiervliet G, Gasmi M et al. Efficacy of the endoscopic rendez-vous technique for the reconstruction of complete esophageal disruptions. Endoscopy 2016; 48: 179-183

[5] Bueno R, Swanson SJ, Jaklitsch MT et al. Combined antegrade and retrograde dilation: a new endoscopic technique in the management of complex esophageal obstruction. Gastrointest Endosc 2001; 54 : 368-372

\section{Bibliography}

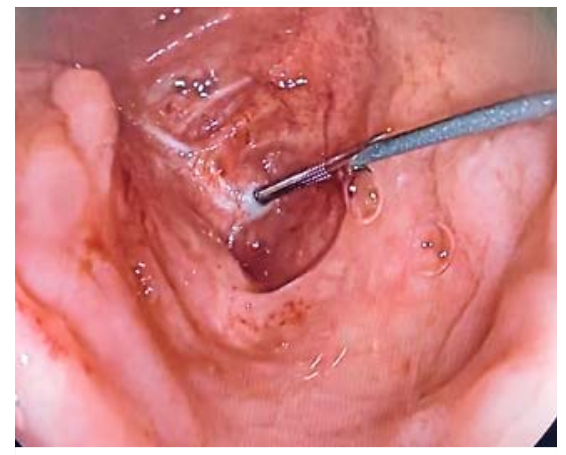

- Fig. 3 Endoscopic view of the proximal part of the disrupted esophagus showing the rendezvous between the retrograde endoscope and a catheter with a hydrophilic guidewire that had been passed through the obstructed pharyngocolonic anastomosis from the antegrade endoscope.
Endoscopy 2020; 52: E428-E429

DOI 10.1055/a-1158-8682

ISSN 0013-726X

published online 6.5 .2020

(C) 2020. Thieme. All rights reserved.

Georg Thieme Verlag KG, Rüdigerstraße 14,

70469 Stuttgart, Germany

\section{ENDOSCOPY E-VIDEOS}

https:/|eref.thieme.de/e-videos

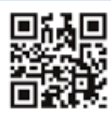

Endoscopy E-Videos is a free access online section, reporting on interesting cases and new techniques in gastroenterological endoscopy. All papers include a high quality video and all contributions are freely accessible online.

\section{Corresponding author}

\author{
Xavier Benoît D'Journo, MD, PhD \\ Department of Thoracic Surgery, North \\ Hospital, Aix-Marseille University, APHM, \\ Marseille, France \\ xavier.djourno@ap-hm.fr
}

This section has its own submission website at https://mc.manuscriptcentral.com/e-videos 